\title{
Research Article \\ IDENTIFICATION OF MAIZE LINE OF MANIPUR CONTAINING crtRB1 3'TE FAVOURABLE ALLELE USING MOLECULAR MARKER
}

\author{
YAIKHOM VIVEKANANDA* ${ }^{* 1}$, WAREPAM JESMI DEVI2, JADUMANI AHONGSHANGBAM ${ }^{1}$, SINGH N.B. ${ }^{1}$ AND LAISHRAM J.M. ${ }^{1}$ \\ 1Department of Genetics \& Plant Breeding, College of Agriculture, Central Agricultural University, Imphal, 795004, India \\ 2Department of Biotechnology, H.K. School of Life Sciences, Assam University, Silchar, 788011, India \\ *Corresponding Author: Email - boneybi@gmail.com
}

Received: May 19, 2018; Revised: May 26, 2018; Accepted: May 27, 2018; Published: May 30, 2018

\begin{abstract}
Vitamin A is one of the essential nutrients for normal functioning and growth in our body. Biofortification of vitamin A in the crop (Maize) is an economical way to overcome vitamin A deficiency. The crtRB1 is an important gene in the carotenoid pathway which increases $\beta$-carotene accumulation in maize. Selecting the lines having favourable allele is a cost-effective method alternative to high performance liquid chromatography (HPLC). In the present study, we screened hundred maize lines of Manipur derived from CAU-87 using a crtRB1 3'TE gene-specific marker and found that three lines viz., CAU-87-9, CAU-87-12, CAU-87-28 contained the favourable allele which can be utilized for maize improvement programme.
\end{abstract}

Key words- Maize, $\beta$-carotene, crtRB1 gene, Manipur

Citation: Yaikhom Vivekananda, et al., (2018) Identification of Maize Line of Manipur Containing crtRB1 3'TE Favourable Allele Using Molecular Marker. International Journal of Genetics, ISSN: 0975- 2862 \& E-ISSN: 0975-9158, Volume 10, Issue 5, pp.-434-437.

Copyright: Copyright@2018 Yaikhom Vivekananda, et al., This is an open-access article distributed under the terms of the Creative Commons Attribution License, which permits unrestricted use, distribution and reproduction in any medium, provided the original author and source are credited.

Academic Editor / Reviewer: Ch. Dhananjoy Singh

\section{Introduction}

Vitamin A or Retinol is one of the important essential nutrient required in our body for normal growth and functioning [1]. World Health Organization (WHO) reported that due Vitamin A Deficiency (VAD) alone, globally around0.25 to 0.5 million children become blind every year and half of them died within 12 months of losing sight. Since our body cannot synthesize Vitamin $A$ of its own, it needs to be provided as provitamin $A$, carotenoids, including $\alpha$-carotene, $\beta$-carotene and $\beta$ cryptoxanthin [2] which further converted into vitamin A through metabolism. One of the sustainable and cost-efficient method to overcome vitamin A deficiency is through biofortification of $\beta$-carotene into food crops. Maize is one of the important food crops and together with rice and wheat, it accounts at least $30 \%$ of the food calories to more than 4.5 billion people [3]. It is also one of the selected crops for vitamin A biofortification, which is one of the world's most widely grown cereal crop and is ranked third among cereal [4]. Biofortification of vitamin A in Maize is an economical way to overcome VAD, globally. $[2,5]$. The four predominant carotenoids found in maize are $\beta$-carotene, $\beta$-cryptoxanthin, zeaxanthin and lutein. However, $\beta$-carotene has the most provitamin $A$ activity among the carotenoid found $[6,7]$. Recent research in maize has demonstrated three important genes in the accumulation of provitamin $\mathrm{A}$ in grain viz., Phytoene synthase1 (Y1 or Psy1) which catalyses the formation of phytoene and responsible for the yellow colour of grains [8]; IcyE (lycopene epsilon cyclase) which converts lycopene to a-lycopene with association of other gene and natural occurring mutant allele of this gene with less functionality divert the more lycopene towards $\beta$-carotene branch enhancing more flux towards provitamin A accumulation; crtRB1 gene ( $\beta$-carotene hydroxylase 1) an important gene associated with $\beta$-carotene accumulation which converts $\beta$-carotene (having $100 \%$ provitamin $A$ activity) to $\beta$-cryptoxanthin (having $50 \%$ pro-vitamin $\mathrm{A}$ activity) and zeaxanthin (having $0 \%$ pro-vitamin $\mathrm{A}$ activity). The naturally occurring variation of this gene can increase more accumulation of $\beta$-carotene by preventing further conversion into other compounds $[1,2,7,9]$. Quantifying of provitamin A contain using high performance liquid chromatography (HPLC) is costly and time consuming; marker-assisted selection (MAS) using DNA markers can help in identifying the genotypes with high accumulation of provitamin A. [10,11]. Psy1 can increase $\beta$ - carotene accumulation by increasing the quantity of substrate in the carotenoid biosynthesis pathway. The favourable allele of Psy1 is nearly fixed in the tropical maize and favourable alleles of IcyE and crtRB1, however, are uncommon in tropical germplasm and may be targeted for high provitamin A [12] maize breeding in the tropical region. The crtRB1 had a huge and significant impact on enhancing $\beta$ carotene and total provitamin A content, regardless of genetic constitution for ICyE- 5'TE and Marker Assisted Selection (MAS) for favourable 'allele 1' of crtRB1 can lead to speedy doubling or more of total provitamin A concentration while MAS for favourable 'allele 4' of IcyE normally results in 20-30\% increase in total provitamin A concentration. Three polymorphisms of crtRB1 have been identified through mapping approach viz., 5'TE (in the 5'- Untranslated Region), InDel4 (in the coding region) and 3'TE (spanning the sixth exon and 3'- Untranslated Region) and PCR based co-dominant markers were identified for all the three polymorphisms helping in improvement of provitamin $A$ content in maize through Marker Assisted Selection [1,2]. The 3'TE polymorphism of crtRB1 gene (that spans the 6th exon and The 3'TE polymerism of crtRB1 gene has three alleles that have a varying degree of $\beta$-carotene accumulation in maize kernel viz. allele 1 without TE insertion (543 bp), allele 2 having 325 bp insertion (296 bp +875 bp) and allele 3 having $1250 \mathrm{bp}$ insertion (296 bp+1221 bp+1880 bp). The allele 1 (favourable allele) enhanced the $\beta$-carotene concentration by reducing transcript expression of the crtRB1 gene, with an average increase of $6.50 \mu \mathrm{g} / \mathrm{g} \beta$-carotene in maize endosperm comparing with unfavourable allele (allele 2 and allele 3) [1, 2]. The North-Eastern Himalayan region of India including the state of Manipur is rich in maize diversity which is supported by the Asiatic origin of maize [13]. 


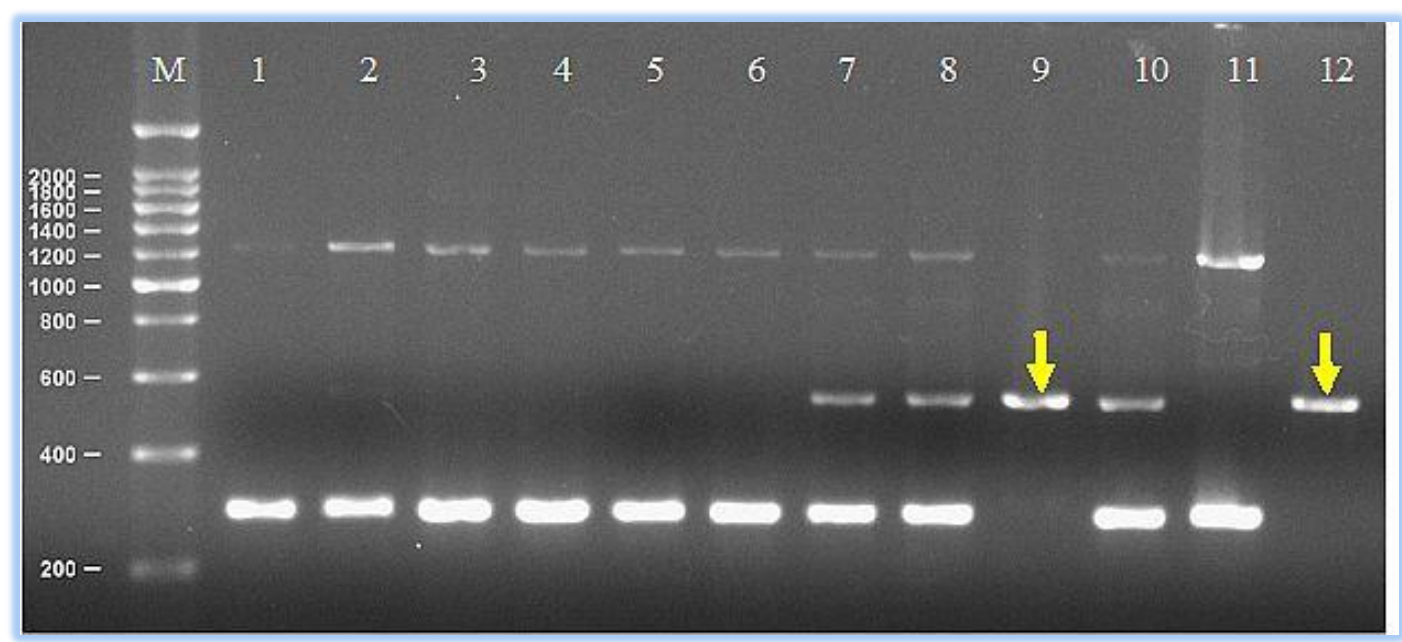

Fig-1 Allelic variation of 3' TE of crtRB1 gene in maize lines of Manipur. Lane M- 200bp DNA ladder; Lane 1 to Lane 12- line CAU-87-1 to CAU-87-12. Lane 9, 12- lines with favourable allele i.e., CAU-87-9, CAU-87-12.

Table-1 Allelic polymorphism of 3'TE of crtRB1 gene in Maize lines of Manipur

\begin{tabular}{|c|c|c|c|c|c|}
\hline SN & Lines(Progeny from CAU87) & Allelic size(bp) & Sl. No. & Lines(Progeny from CAU87) & Allelic size (bp) \\
\hline 1. & CAU-87-1 & $1221+296$ & 51. & CAU-87-51 & $1221+296$ \\
\hline 2. & CAU-87-2 & $1221+543+296$ & 52. & CAU-87-52 & $543+296$ \\
\hline 3. & CAU-87-3 & $1221+296$ & 53. & CAU-87-53 & $1221+296$ \\
\hline 4. & CAU-87-4 & $1221+296$ & 54. & CAU-87-54 & $1221+543+296$ \\
\hline 5. & CAU-87-5 & $1221+296$ & 55. & CAU-87-55 & $1221+296$ \\
\hline 6. & CAU-87-6 & $1221+296$ & 56. & CAU-87-56 & $1221+296$ \\
\hline 7. & CAU-87-7 & $1221+543+296$ & 57. & CAU-87-57 & 296 \\
\hline 8. & CAU-87-8 & $1221+543+296$ & 58. & CAU-87-58 & $1221+296$ \\
\hline 9. & CAU-87-9 & 543 & 59. & CAU-87-59 & $1221+296$ \\
\hline 10. & CAU-87-10 & $1221+543+296$ & 60. & CAU-87-60 & 296 \\
\hline 11. & CAU-87-11 & $1221+296$ & 61. & CAU-87-61 & 296 \\
\hline 12. & CAU-87-12 & 543 & 62. & CAU-87-62 & $543+296$ \\
\hline 13. & CAU-87-13 & $543+296$ & 63. & CAU-87-63 & 296 \\
\hline 14. & CAU-87-14 & $1221+543+296$ & 64. & CAU-87-64 & $543+296$ \\
\hline 15. & CAU-87-15 & $1221+296$ & 65. & CAU-87-65 & $1221+543+296$ \\
\hline 16. & CAU-87-16 & $1221+296$ & 66. & CAU-87-66 & $1221+543+296$ \\
\hline 17. & CAU-87-17 & $1221+296$ & 67. & CAU-87-67 & 296 \\
\hline 18. & CAU-87-18 & $1221+296$ & 68. & CAU-87-68 & $543+296$ \\
\hline 19. & CAU-87-19 & $1221+543+296$ & 69. & CAU-87-69 & $543+296$ \\
\hline 20. & CAU-87-20 & $1221+543+296$ & 70. & CAU-87-70 & $1221+543+296$ \\
\hline 21. & CAU-87-21 & $1221+296$ & 71. & CAU-87-71 & $543+296$ \\
\hline 22. & CAU-87-22 & $1221+296$ & 72. & CAU-87-72 & $1221+296$ \\
\hline 23. & CAU-87-23 & $1221+296$ & 73. & CAU-87-73 & $543+296$ \\
\hline 24. & CAU-87-24 & $1221+543+296$ & 74. & CAU-87-74 & $1221+543+296$ \\
\hline 25. & CAU-87-25 & $1221+296$ & 75. & CAU-87-75 & $543+296$ \\
\hline 26. & CAU-87-26 & $1221+543+296$ & 76. & CAU-87-76 & $1221+296$ \\
\hline 27. & CAU-87-27 & $1221+543+296$ & 77. & CAU-87-77 & $1221+296$ \\
\hline 28. & CAU-87-28 & 543 & 78. & CAU-87-78 & $1221+296$ \\
\hline 29. & CAU-87-29 & $1221+296$ & 79. & CAU-87-79 & 296 \\
\hline 30. & CAU-87-30 & $1221+296$ & 80. & CAU-87-80 & 296 \\
\hline 31. & CAU-87-31 & $1221+296$ & 81. & CAU-87-81 & 296 \\
\hline 32. & CAU-87-32 & $543+296$ & 82. & CAU-87-82 & 296 \\
\hline 33. & CAU-87-33 & $1221+296$ & 83. & CAU-87-83 & 296 \\
\hline 34. & CAU-87-34 & $1221+296$ & 84. & CAU-87-84 & 296 \\
\hline 35. & CAU-87-35 & 296 & 85. & CAU-87-85 & 296 \\
\hline 36. & CAU-87-36 & $1221+296$ & 86. & CAU-87-86 & $1221+296$ \\
\hline 37. & CAU-87-37 & 296 & 87. & CAU-87-87 & 296 \\
\hline 38. & CAU-87-38 & $1221+296$ & 88. & CAU-87-88 & 296 \\
\hline 39. & CAU-87-39 & $543+296$ & 89. & CAU-87-89 & $1221+296$ \\
\hline 40. & CAU-87-40 & $543+296$ & 90. & CAU-87-90 & $1221+543+296$ \\
\hline 41. & CAU-87-41 & $543+296$ & 91. & CAU-87-91 & $1221+296$ \\
\hline 42. & CAU-87-42 & 296 & 92. & CAU-87-92 & $1221+296$ \\
\hline 43. & CAU-87-43 & 296 & 93. & CAU-87-93 & $1221+296$ \\
\hline 44. & CAU-87-44 & 296 & 94. & CAU-87-94 & $1221+296$ \\
\hline 45. & CAU-87-45 & 296 & 95. & CAU-87-95 & $1221+296+543$ \\
\hline 46. & CAU-87-46 & 296 & 96. & CAU-87-96 & $1221+296$ \\
\hline 47. & CAU-87-47 & $543+296$ & 97. & CAU-87-97 & $1221+296$ \\
\hline 48. & CAU-87-48 & 296 & 98. & CAU-87-98 & $543+296$ \\
\hline 49. & CAU-87-49 & 296 & 99. & CAU-87-99 & 296 \\
\hline 50. & CAU-87-50 & 296 & 100. & CAU-87-100 & $543+296$ \\
\hline
\end{tabular}




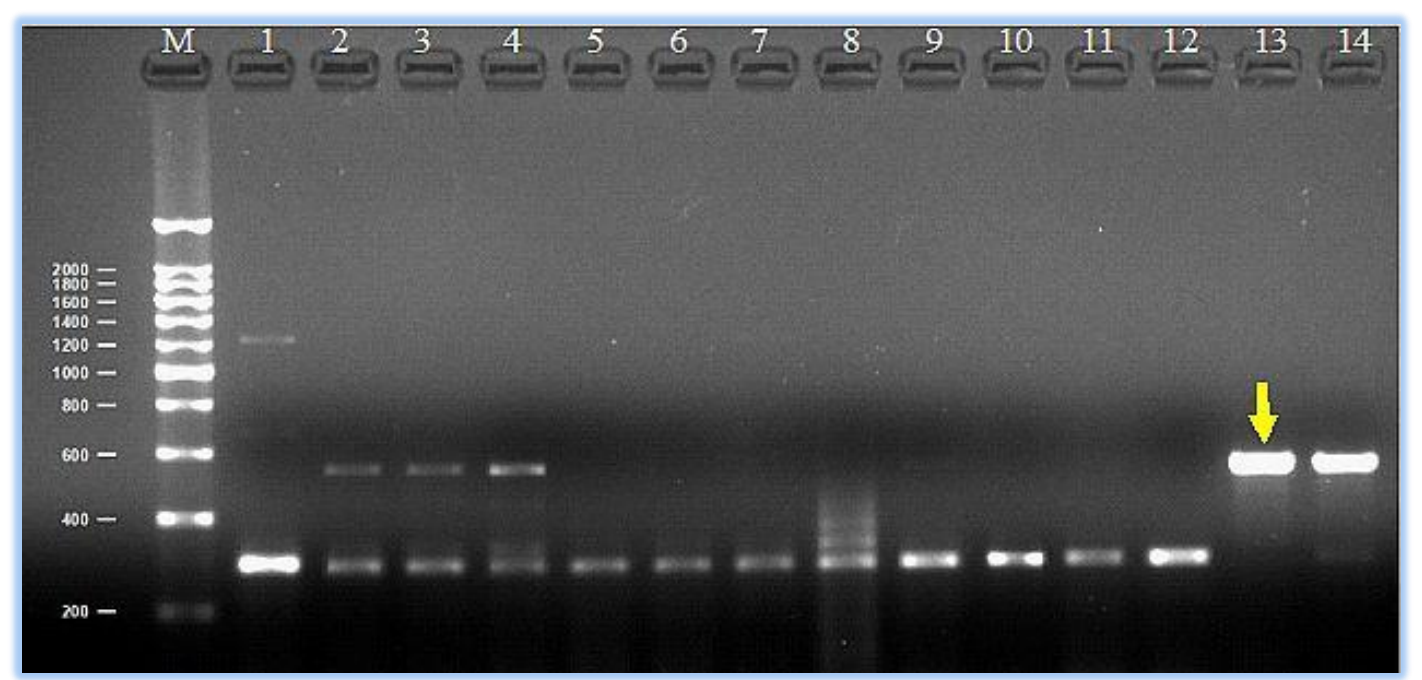

Fig-2 Allelic variation of 3' TE of crtRB1 gene in maize lines of Manipur. Lane M-200bp DNA ladder; lane 1 to lane 12-line CAU-87-38 to CAU-87-49; lane 13, 14-line CAU87-28 and CAU-87-32. Lane 13-line with favourable allele i.e., CAU-87-28.

Recent genotyping of maize cultivars of Manipur [14] have found that CAUCH 87 or CAU 87 landrace of Manipur contained favourable allele (543 bp) of crtRB1 3'TE gene in heterozygous condition with unfavourable allele (296 bp). Since the presence of $296 \mathrm{bp}$ (unfavourable allele with the insertion of $325 \mathrm{bp}$ in 3'TE region) can lower the $\beta$-carotene accumulation. The present study aims at selecting the lines or progeny derived from CAU-87 landrace having favourable allele 1 (543 bp).

\section{Materials and Method \\ Plant Materials}

A hundred seeds (kernels) randomly selected from seed lot of self-population of CAU 87 were planted in the laboratory and later transplanted in the field. Each plant was assigned with specific code for the study. The lines or progeny (from the single kernel) derived from CAU 87 were screened for the presence of favourable allele.

\section{DNA extraction}

DNA was extracted from the leaves of 15 days old seedlings using SDS procedure with slight modification [15].

\section{PCR analysis}

Screening for favourable allele 1 (543bp) was done using crtRB1 3'TE genespecific primers, crtRB1-3'TE-F: ACACCACATGGACAAGTTCG, crtRB1-3'TE-R1: ACACTCTGGCCCATG AACAC and crtRB1-3'TE-R2: ACAGCAATACAGGGGACCAG $[2,7,10]$. The primers were synthesized and purified by IDT. PCR was performed with a total volume of $25 \mu \mathrm{L}$, containing $1 \mu \mathrm{L}$ crude DNA, $2.5 \mu \mathrm{L}$ of PCR buffer(supplied with Taq polymerase), $0.2 \mathrm{mM}$ each of dNTPs, $0.3 \mu \mathrm{M}$ of each primer and $2 \mathrm{U}$ of Taq DNA Polymerase (GeNei, Bengaluru, India). PCR amplification (2720 Thermal Cycler, Applied Biosystems, California, USA) was carried out using the standard cycle conditions [7]. The PCR products were separated by electrophoresis on $2 \%$ agarose gel. The gels were stained with ethidium bromide and detected under Gel Doc XR+ with Image Lab Software (Bio-Rad, California,USA).

\section{Results and Discussion}

Out of the hundred lines screened for the presence of a favourable allele of crtRB1 3'TE gene, three lines i.e., CAU-87-9, CAU-87-12 and CAU-87-28 have found to contain the favourable allele 1 (543 bp) in homozygous condition. Thirtytwo lines have $543 \mathrm{bp}$ in heterozygous conditions ( 16 lines having $543 \mathrm{bp}+296 \mathrm{bp}$ allele and 16 lines having 1221 bp +543 bp +296 bp allele) which can be further self for recovering progeny having favourable (543bp) in homozygous condition. Remaining progeny or lines have an unfavourable allele of 3'TE gene i.e., either $296 \mathrm{bp}$ or $1221+296 \mathrm{bp}$ which is given in table 1. Presence of favourable allele of
crtRB1 3'TE alone can double the $\beta$-carotene content [2] and the line having that allele can be utilized for marker-assisted backcross for improvement vitamin $A$ content in maize breeding programme.

\section{Conclusion}

The present genotyping of maize lines of Manipur for the presence of a favourable allele (543 bp) of crtRB1 3'TE found that three lines i.e., CAU-87-9, CAU-87-12 and CAU-87-28 derived from CAUCH 87 have the favourable allele and can be utilized for marker-assisted backcross programme for improvement of vitamin $A$ content in maize.

Application of research: Improvement of maize for vitamin A content.

Research Category: Genetics and Plant Breeding

\author{
Abbreviations: \\ $\%$ : Percentage \\ $\mu \mathrm{g}:$ Microgram \\ $\mu \mathrm{L}$ : Microlitre \\ $\mu \mathrm{M}$ : Miromolar \\ 3' TE: 3' Transposable element \\ 3' UTR: Untranslated region \\ bp: Base pair \\ crtRB1: $\beta$ - carotene hydroxylase 1 \\ DNA: Deoxyribonucleic Acid \\ dNTP: Deoxyribonucleotide Triphosphate \\ g: Gram \\ HPLC: High Performance Liquid Chromatography \\ IDT: Integrated DNA Technologies \\ IcyE: Lycopene epsilon cyclase \\ MAS: Marker Assisted Selection \\ mM: Milimolar \\ Psy 1 or Y1: Phytone synthase 1 \\ SDS: Sodium dodecyl sulphate \\ U: unit \\ VAD: Vitamin A Deficiency \\ WHO: World Health Organisation
}

Acknowledgement / Funding: Author thankful to Central Agricultural University, Imphal, 795004, India

*Research Guide or Chairperson of research: JM Laishram

University: Central Agricultural University, Imphal, 795004, India 
Research project name or number: PhD Thesis

\section{Author Contributions: All author equally contributed}

Author statement: All authors read, reviewed, agree and approved the final manuscript

\section{Conflict of Interest: No Conflict of Interest}

Ethical approval: This article does not contain any studies with human participants or animals performed by any of the authors.

\section{References}

[1] Vignesh M., Hossain F., Nepolean T., Choudhary M., Saha S., Bhat J.S., Prasanna M.B., Gupta H.S. (2012) Indian J. Genet., 72,189-194.

[2] Yan J.B., Kandianis C.B., Harjes C.E., Bai L., Kim E., Yang X.H., Skinner D., Fu Z.Y., Mitchell S., Li Q., Fernandez M.G.S., Zaharieva M., Babu R., Fu Y., Palacios N., Li J.S., DellaPenna D., Brutnell T., Buckler E.S., Warburton M.L., Rocheford T. (2010) Nat Genet., 2(4),322-7.

[3] Shiferaw B., Prasanna B. M., Hellin J., Banziger M. (2011) Food Security,3, 307-327.

[4] Ayisi K.K., Poswall M.A.L. (1997) Europ. J. Agron., 16,151-159.

[5] Tanumihardjo S.A., Bouis H., Hotz C., Meenakshi J.V., McClafferty B. (2008) Compr. Rev. Food Sci. Food Safety,7, 329-334.

[6] Harjes E.C., Rocheford R.T., Ling B., Brutnell P.T., Kandianis B.C., Sowinski G.S., Stapleton E.A., Vallabhaneni R., Williams M., Wurtzel T.E., Yan J., Buckler S.E. (2008) Sci., 319, 330-333.

[7] Selvi T.D., Senthil N., Yuvaraj N., John Joel A., Mahalingam A., Nagarajan P., Vellaikumar S., Srimathi P., Raveendran M. and Nepolean T. (2014) Food Biotechnology, 28, 41-49.

[8] Li Q., Farre G., Naqvi S., Breitenbach J., Sanahuja G., Bai C., Sandmann G., Capell T., Christou P., Zhu C. (2010) Transgenic Res., 19,1053-1068.

[9] Babu R., Rojas N.P., Gao S., Yan J., Pixley K. (2012) Theor. Appl. Gene., 126, 389-399.

[10] Muthusamy V., Hossain F., Thirunavukkarasu N., Choudhary M., Saha, S. (2014) PLOS ONE, 9(12), 1-22.

[11] Zunjare R.U., Hossain F., Muthusamy V. (2017) Plant Breed., 136, 872-880.

[12] Fu Z., Chai Y., Zhou Y., Yang X., Warburton M.L., Xu S., Cai Y., Zhang D., Li J., Yan J. (2013) TheorApp/Genet, 126, 923-935.

[13] Anjula P., Semwal D.P., Ahlawat S.P., Sharma S.K. (2015) Maize (Zea mays): Collection Status, Diversity Mapping and Gap Analysis, National Bureau of Plant Genetic Resources, New Delhi, India, 34.

[14] Chuwanghijam, Dhananjoychingangbam, Thangjamsurchandra, Laishram J.M. (2017) International Journal of Agricultural Science and Research, 7(1),115-120.

[15] Zheng K., Subudhi P.K., Domingo J., Magpantay G. and Huang N. (1995) Rice Genetics Newsletter, 12, 255-258. 